\title{
"E QUE É A CIDADE, SE NÃO FOR O POVO": CONTRIBUIÇÕES DO MODELO DE DEMOCRACIA PARTICIPATIVA PARA A CONCRETIZAÇÃO DO DIREITO À CIDADE
}

\author{
Carla Maria Peixoto Pereira* \\ Luciana Costa da Fonseca**
}

\begin{abstract}
Resumo: Objetiva-se neste artigo analisar como o modelo de democracia participativa pode contribuir para a concretização do direito à cidade, o qual, segundo Henri Lefebvre e David Harvey, tem como um de seus vieses principais a questão democrática. Neste contexto, insta investigar de que forma o modelo de democracia participativa pode contribuir para a concretização do direito à cidade, apresentando a teoria de democracia participativa baseada na concepção de pacto social de Jean-Jacques Rousseau como modelo cujo fundamento melhor se adequa à gestão democrática das cidades. Para a discussão do tema, a abordagem metodológica é qualitativa e pautada em fontes bibliográficas. Conclui-se que o modelo de democracia participativa contribui de diversas formas para a concretização do direito à cidade.
\end{abstract}

Palavras-chave: Direito à Cidade; Democracia Participativa; Gestão Democrática; Cidade; Pacto Social.

\section{“WHAT IS THE CITY BUT THE PEOPLE": CONTRIBUTIONS OF THE PARTICIPATORY DEMOCRACY PARADIGM TO THE REALIZATION OF THE RIGHT TO THE CITY}

\begin{abstract}
This article intends to analyze how the participatory democracy paradigm may contribute to the realization of the right to the city, which has as one of its main particulars the democratic issue. For that, it's important to investigate how the participatory democracy paradigm may contribute to the realization of the right to the city, presenting the theory of participatory democracy based on the idea of social pact by Jean-Jacques Rousseau as the paradigm that better suits the democratic management of cities. The methodological approach is qualitative and based on bibliographical sources. It was concluded that the participatory democracy padarigm contributes in many ways to the realization of the right to the city.
\end{abstract}

Keywords: Right to the City; Participatory Democracy; Democratic Management; City; Social Pact.

\footnotetext{
* Mestranda em Direito, Políticas Públicas e Desenvolvimento Regional pelo CESUPA. Especialista em Direito do Trabalho (FGV/Rio) e Direito Constitucional (Universidade Anhanguera-Uniderp). Membro do Grupo de Pesquisa CNPq Direito, Desenvolvimento Sustentável e Amazônia e do Grupo de Pesquisa CNPq Concretização dos Direitos Fundamentais e sua fundamentação: abordagens a partir da teoria do processo, da análise econômica e das teorias da justiça (linha de pesquisa: Teorias da Justiça e Políticas Públicas: fundamentação. Advogada.

${ }^{* *}$ Doutorado em Direito pela Pontifícia Universidade Católica de São Paulo (2006), Mestrado em Direito pela Pontifícia Universidade Católica de São Paulo (1999), Especialização em Direito Sanitário pela Faculdade de Direito e pela Faculdade de Saúde Pública da USP (2001), Graduação em Direito pela Universidade Federal do Pará (1993). Atualmente é professora adjunta da Universidade Federal do Pará - UFPA e professora da Grdualção e Pós - Graduação do CESUPA. Coordenadora do Curso de Especialização em Direito Ambiental do Centro Universitário do Pará e Escola Superior de Advocacia da OAB/PA. Advogada.
}

Rev. de Direito Urbanístico, Cidade e Alteridade | e-ISSN: 2525-989X | Porto Alegre | v. 4 | n. 2 | p. 16 - 33 | Jul/Dez. 2018 


\section{INTRODUÇÃO}

Objetiva-se neste artigo analisar como o modelo de democracia participativa pode contribuir para a concretização do direito à cidade.

Há muito se discute sobre o que é cidade e a quem ela pertence. O personagem shakespeariano Sicínio na peça "Coriolano", de 1608, indaga o que seria a cidade se não o seu povo, obtendo como resposta dos cidadãos de que "a cidade é o próprio povo" (SHAKESPEARE, online). Porém, esta ideia de pertencimento do espaço urbano aos seus habitantes só foi profundamente construída mais de trezentos anos após este questionamento ter sido feito.

A ideia de direito à cidade surgiu em 1968 e foi cunhado pelo filósofo francês Henri Lefebvre (2001), o qual conclama em seu livro homônimo por uma nova forma de se urbanizar, por meio de uma democracia urbana renovada. David Harvey (2008; 2014), ao apropriar-se deste conceito propôs que este detém um viés revolucionário, devendo a população apropriarse desse direito e interromper a cruel produção capitalista do espaço, de modo que decidam democraticamente como esta organização espacial deve se dar.

Percebe-se, portanto, que o direito à cidade tem como um de seus vieses principais a questão democrática, tendo sido reconhecido no direito internacional na Carta Mundial do Direito à Cidade, em 2004, e positivado no ordenamento jurídico brasileiro no Estatuto da Cidade em 2001 e no Estatuto da Metrópole em 2015, o que enseja a urgente discussão sobre a necessidade de participação popular na construção de diretrizes que guiam a construção do espaço urbano.

Neste contexto, insta investigar de que forma o modelo de democracia participativa pode contribuir para a concretização do direito à cidade, apresentando a teoria de democracia participativa como modelo cujo fundamento melhor se adequa à gestão democrática das cidades. Deste modo, este artigo organiza-se da seguinte forma: no primeiro tópico será explicado no que consiste o direito à cidade e sua importância para a democracia urbana, sendo apresentadas as teorias de Henri Lefebvre e David Harvey, duas referências nesta temática, cujos estudos desenvolveram este direito antes de ele passar a ser positivado no direito internacional e em nossa legislação interna.

No seguinte tópico, apresentar-se-á a teoria do modelo de democracia participativa baseada na concepção de pacto social de Jean-Jacques Rousseau. E, ao final, discorrer-se-á 
sobre as contribuições que este modelo pode ofertar para a gestão democrática da cidade e, consequentemente, à concretização do direito à cidade.

\section{O DIREITO À CIDADE: BUSCA PELA DEMOCRACIA URBANA}

O direito à cidade é um direito humano coletivo (HARVEY, 2014) ainda pouco conhecido, cujo desenvolvimento teórico teve origem na década de 1960, por Henri Lefebvre. Lefebvre (2001), inconformado com a construção meramente tecnocrata da cidade, sugere o direito à cidade como uma forma de se rever a construção do espaço pelo capital, clamando por uma renovação deste modo de construção por meio de uma democracia e humanismo revisitados.

O processo de burocratização da cidade teve seu início com a industrialização, no qual a cidade perde seu valor de uso e passa a ter valor de troca. Frisa-se que, ainda que sejam fenômenos que detém forte influência um no outro, são distintos, de modo que a problemática urbana se descola da industrialização e alcança até mesmo o rural, retirando deste suas características campesinas e contaminando-o com valores urbanos. Hodiernamente, este processo persiste, reforçando a sociedade do consumo em que vivemos, transformando todos os habitantes da cidade em consumidores (LEFEBVRE, 2001, 2008). A cidade, portanto, detém duplo viés, sendo o local do consumo e algo em si mesmo a ser consumido. Neste contexto, tudo na cidade passa a ter valor de troca, adquirindo status de mercadoria.

[...] A cidade e a realidade urbana dependem do valor de uso. O valor de troca e a generalização da mercadoria pela industrialização tendem a destruir, ao subordinálas a si, a cidade e a realidade urbana, refúgios do valor de uso, embriões de uma virtual predominância e de uma revalorização do uso. (LEFEBVRE, 2001, p. 14) (sic)

Esta mudança se dá por a cidade ser “uma mediação entre as mediações” (LEFEBVRE, 2001, p. 52), ou seja, em razão de as modificações no espaço urbano se darem por conta das relações sociais nele desenvolvidas, bem como pelas instituições dominantes que fazem parte da sociedade. A cidade que vemos, portanto, é um meio termo entre esses dois fatores.

Esta perspectiva, para Lefebvre (2001), é inaceitável, pois que a cidade não deveria ter um viés de mercadoria, mas de obra de arte, o que faz com que seu espaço passe a ter valor de uso, e não de troca. Neste sentido, Lefebvre (2008, p. 80) aduz que "o crescimento quantitativo da produção econômica produziu um fenômeno qualitativo que se traduz, ele próprio, por uma problemática nova: a problemática urbana". 
Para o teórico, é um consenso que a cidade moderna se caracteriza por abrigar os centros de decisão (que englobam todos os canais de informação e formação os quais influenciam a cultura e a ciência na sociedade), assim como por organizar como se dará a exploração do proletariado pelas classes dominantes, as quais interveem ativa e diretamente nos meios de produção (LEFEBVRE, 2001).

Neste cenário, a problemática urbana teve seu surgimento facilitado por ter o capital fácil acesso ao território urbano, bem como aos seu centro de decisões. Com as conjugações destes fatores, iniciou-se a construção de empreendimentos os quais, por meio da especulação imobiliária e financeirização do capital, possibilitou a exploração dos citadinos e de seu espaço, formando um ciclo vicioso econômico (LEFEBVRE, 2001).

Tal ciclo é composto pelas classes dominantes e pelas classes trabalhadoras. As classes dominantes são aquelas que são donas do meio de produção e que de fato determinam como o capital será empregado, bem como detêm propriedade de seu tempo. As classes trabalhadoras (composta pelo restante da sociedade) configura-se por sua grande heterogeneidade, extrapolando o proletariado operário e englobando os que não são donos do próprio tempo. Graças à sua grande diversidade, é extremamente fragmentada, o que reflete na sua pauta de necessidades e contribui para sua desorganização (LEFEBVRE, 2001; HARVEY, 2014).

Outra consequência da problemática urbana foi a expulsão da classe trabalhadora do centro para as franjas da cidade. Este fenômeno seria fomentado pelas classes dominantes, de modo a proteger seus privilégios os quais estavam ameaçados pelo proletariado. Com a segregação territorial da classe trabalhadora para locais territorialmente cada vez mais distantes dos centros de decisão, impossibilita-se a promoção de uma verdadeira democracia urbana. Esta ressignificação da concepção de habitar a cidade, por meio da proteção da propriedade privada, promove uma "urbanização desurbanizante e desurbanizada", o que destrói a ideia de cidade como obra de arte para o proletariado (LEFEBVRE, 2001, p. 25).

\footnotetext{
O urbano é a obsessão daqueles que vivem na carência, na pobreza, na frustração dos possíveis que permanecem como sendo apenas possíveis. Assim, a integração e a participação são a obsessão dos não-participantes, dos não-integrados, daqueles que sobrevivem entre os fragmentos da sociedade possível e das ruínas do passado: excluídos da cidade, às portas do "urbano" [...] Poderá a vida urbana recuperar e intensificar as capacidades de integração e de participação da cidade, quase inteiramente desaparecidas, e que não podem ser estimuladas nem pela via autoritária, nem por prescrição administrativa, nem por intervenção de especialistas?. (LEFEBVRE, 2001, p. 102-104) (sic)
} 
Até o surgimento da problemática urbana, objetivava-se o habitar do citadino-cidadão, ou seja, que este pudesse efetivamente participar da vida social da cidade, a qual era construída por meio das discussões e trocas de ideias, pelos encontros das pessoas e pelos embates políticoideológicos que se davam entre os moradores da cidade, fruto de uma verdadeira coexistência. Ocorre que com a mudança de significado de habitar há uma perda desta consciência urbana o que, juntamente com a violação do aspecto sagrado do solo (quando este passa a ter valor de troca), faz com que passe a predominar naquele espaço o habitat (LEFEBVRE, 2001).

O habitat se resume apenas ao aspecto físico da moradia, à existência de uma estrutura material; o habitar, porém, não tem essa limitação e é, de fato, o objetivo-fim da cidade, englobando a vida social acima descrita. Lefebvre (2001) diz que apenas a classe do proletariado pode promover a revolução urbana que retorne à predominância da ideia de habitar, enfrentado as questões de segregação socioespacial, de reforma urbana com alteração nos centros de decisão etc, de modo que a cidade volte a ser construída como obra. Neste contexto, o filósofo não oferta um conceito fechado de direito à cidade, mas indica os sentimentos e necessidades que este demanda para ser alcançado.

[...] $\mathrm{O}$ direito à cidade se afirma como um apelo, como uma exigência. [...] $\mathrm{O}$ direito à cidade não pode ser concebido como um simples direito de visita ou de retorno as cidades tradicionais. Só pode ser formulado como direito à vida urbana, transformada, renovada. [...] Lugar de encontro, prioridade de valor de uso, inscrição no espaço de um tempo promovido à posição de supremo bem entre os bens, encontre sua base morfológica, sua realização prático-sensível. O que pressupõe uma teoria integral da cidade e da sociedade urbana que utilize os recursos da ciência e da arte. (LEFEBVRE, 2001, p. 117-118)

Neste sentido, deve-se buscar o espaço urbano construído pelo trabalho produtivo e pela festa do encontro, manifestando-se o direito à cidade no “[...] direito à liberdade, à individualização na socialização, ao habitat e ao habitar. O direito à obra (à atividade participante) e o direito à apropriação (bem distinto do direito à propriedade) estão implicados no direito à cidade” (LEFEBVRE, 2001, p. 134).

$\mathrm{O}$ direito à cidade é direito inscrito no rol dos novos direitos dos citadinos-cidadãos, devendo ser melhor explorado por seus titulares por ser indispensável ao exercício de outros direitos dos moradores da cidade, assim como por ser um direito cuja existência se impõe às sociedades que se tornam urbanas (LEFEVBRE, 1990).

Aderindo integralmente ao que Lefebvre $(1990 ; 2001 ; 2008)$ propõe, o geógrafo inglês David Harvey $(2005 ; 2008 ; 2014)$ adiciona ao direito à cidade uma dimensão política. Inicialmente, frisa-se que Harvey adverte que o direito à cidade é um conceito cujo significado 
é determinado pelo ator que o domina, podendo ser utilizado para legitimar ações e discursos que contrariam a proposta Lefebvriana de habitar.

Para o teórico, que utiliza a teoria econômica marxista na construção de sua própria geografia do capitalismo, a conquista do direito à cidade é determinante na busca pela destruição do sistema capitalista e suas estruturas de Estado, poder e classe. Logo, é um direito humano coletivo que tem um viés revolucionário e que não se limita meramente ao acesso a bens e serviços básicos urbanos, mas ao poder de se construir a cidade de acordo com os desejos de seus moradores, e não mais por conta dos ditames do capital (HARVEY, 2014).

Neste contexto, a população deve tomar para si as rédeas do processo de decisão que envolvem o espaço urbanizado, tornando-se este processo endógeno, com consideração e respeito às peculiaridades e desejos dos moradores da cidade. Esta ideia se contrapõe ao que se percebe enquanto produção capitalista do espaço, a qual é, na maioria das vezes, um processo exógeno, cujos atores externos tomam decisões sobre o território, afetando diretamente o espaço físico e relacional de formas muitas vezes irreparáveis.

Harvey (2014) entende que o sistema capitalista depende da urbanização para continuar a sobreviver e a se reproduzir, tendo esta dependência iniciado com a industrialização, a qual é vista como um fenômeno de classes em que se diferenciou a burguesia, o proletariado (que se transformou nos "precariados" do mundo do consumo atual) e os proprietários de terra.

\footnotetext{
De que modo, então, a urbanização capitalista tem sido impulsionada pela necessidade de contornar essas barreiras e aumentar o espaço da atividade capitalista lucrativa? Afirmo aqui que a urbanização desempenha um papel particularmente ativo (ao lado de outros fenômenos, como os gastos militares) ao absorver as mercadorias excedentes que os capitalistas não param de produzir em sua busca de mais-valia. [...] Presenciamos aqui outra mudança de escala no processo de urbanização - mudança que torna difícil entender que o que pode estar acontecendo globalmente seja, em princípio, semelhante aos processos que, por algum tempo, Haussmann administrou com tanta competência na Paris do Segundo Império. (HARVEY, 2014, p. 33-43)
}

Com o avanço da sociedade, tudo se tornou mercadoria, inclusive a qualidade da vida na cidade, que só consegue ser alcançada por aqueles que detêm capital para consumi-la, o que gerou um novo nicho de mercado para o sistema. Em contrapartida, esta nova perspectiva que metamorfoseia valores básicos cria proporcionalmente outros problemas, tais como o aumento da violência e de práticas predatórias (HARVEY, 2014).

Todas estas alterações afligem diretamente o citadino, gerando também uma mudança em seu comportamento, se tornando cada vez mais egoísta e individualista, o que acaba por refletir a própria forma segmentada e segregador de construção do espaço em que está inserido. 


\section{"E QUE É A CIDADE, SE NÃO FOR O POVO": CONTRIBUIÇÕES DO MODELO DE DEMOCRACIA PARTICIPATIVA PARA A CONCRETIZAÇÃO DO DIREITO À CIDADE}

Esta forma de construção do espaço aumenta os conflitos intersociais, bem como desintegra o corpo político coletivo da cidade do encontro, que tem como ideais a noção de cidadania e o sentimento de pertencimento. Em vista disso, vê-se cada vez mais a vigilância privada em espaços públicos e a proliferação de comunidades em condomínios fechados (HARVEY, 2008, 2014).

Há, portanto, uma destruição dos valores de solidariedade e apoio entre os moradores da cidade, que transforma o outro em seu inimigo. Harvey (2014) defende que tudo isto se dá por conta da sacralização do direito à propriedade privada, a qual é utilizado como um instrumento de dominação pelo sistema capitalista sobre as classes precariadas, sob a égide de um discurso progressista de solucionar problemas de escassez que o próprio sistema gera.

Os custos desse processo, arcados por todos os moradores da cidade, em maior ou menor grau, são altos e violam o direito à cidade desta população. Para Harvey (2005, p. 71): “A sobrevivência do capitalismo é atribuída à capacidade constante de acumulação pelos meios mais fáceis. O caminho da acumulação capitalista seguirá por onde a resistência for mais fraca" (sic).

Neste cenário, surgem movimentos sociais urbanos que fazem oposição direta ao modo de produção capitalista do espaço e buscam a retomada do controle sobre a produção e uso do excedente no espaço urbano, de modo que sua gestão seja feita de forma democrática.

Estes movimentos têm um papel importantíssimo na luta pela concretização do direito à cidade, pois que, conforme explicitado alhures, seu significado depende de quem o domina, de modo que é bastante comum as classes dominantes o ressignificarem e construírem a cidade que atendam aos seus próprios interesses utilizando-o como discurso, particularmente com a justificativa de "desenvolvimento" do espaço urbano que leva à melhoria de vida dos citadinos.

\footnotetext{
Uma vez que o processo de urbanização é um dos principais canais de uso, o direito à cidade se configura pelo estabelecimento do controle democrático sobre a utilização dos excedentes na urbanização. [...] O direito à cidade como hoje existe, como se constitui atualmente, encontra-se muito mais confinado, na maior parte dos casos, nas mãos de uma pequena elite política e econômica com condições de moldar a cidade cada vez mais segundo suas necessidades particulares e seus mais profundos desejos. (HARVEY, 2014, p. 61)
}

Deste modo, o direito à cidade deve funcionar como uma pauta unificada entre os movimentos sociais urbanos, assim como deve ser o ideal político e seu principal lema operacional. Ao tomarem ações neste sentido, torna-se mais possível a concretização do direito à cidade e sua consequente gestão democrática do espaço urbano (HARVEY, 2008).

Rev. de Direito Urbanístico, Cidade e Alteridade | e-ISSN: 2525-989X | Porto Alegre | v. 4 | n. 2 | p. 16 - 33 | Jul/Dez. 2018 
[...] Reivindicar o direito de todos a viver em uma casa e um ambiente decentes pode ser visto como o primeiro passo de um movimento revolucionário mais abrangente. [...] Todos aqueles cujo trabalho está envolvido em produzir e reproduzir a cidade têm um direito coletivo não apenas àquilo que produzem, mas também de decidir que tipo de urbanismo que deve ser produzido, onde e como. (HARVEY, 2014, p. 245)

O exercício de democracia da cidade, logo, não se restringe apenas aos movimentos sociais que por ele lutam, mas por todos os seus habitantes, que devem ter a participação em fóruns democráticos de discussão e decisão, ainda que alternativos, garantidos (HARVEY, 2014).

Neste contexto, é incompatível que a gestão democrática da cidade se dê por meio de um modelo que não permita que todos os seus cidadãos participem direta e ativamente do processo de tomada de decisões que envolvem a construção do espaço urbano. Por isso, dentre vários modelos de democracia existentes, acredita-se que o que mais se adequa à concretização do direito à cidade é o modelo de democracia participativa, cuja teoria veremos a seguir.

\section{O MODELO DE DEMOCRACIA PARTICIPATIVA: SUBSÍDIOS TEÓRICOS}

Frank Cunningham (2009) explica que a democracia participativa tem a solidariedade como cerne e que este modelo busca sempre que possível efetuar a tomada de decisão direta pelos envolvidos por meio da discussão, com vistas a chegar em um consenso, em contraponto ao modelo democrático representativo (que se subsome à votação em eleições formais). Neste sentido, a democracia participativa se contrapõe aos modelos de democracia liberal.

Para Lima (2009, p. 253), o modelo de democracia participativa é um "mecanismo por el cual la sociedad civil y los actores locales en general no limitan su acción democrática solamente al voto, sino que participan de los processos de decisión en el ámbito de la administrácion pública"1.

Os casos paradigmáticos deste modelo de democracia datam da década de 1960 e tratam de direitos civis dos estudantes e das mulheres, bem como movimentos pacifistas, os quais, por não terem ferramentas institucionais da democracia representativa para que pudessem expressar suas preocupações, buscaram outra forma de se expressar politicamente e de expor à sociedade seus questionamentos (CUNNINGHAM, 2009).

\footnotetext{
${ }^{1}$ Tradução livre da autora: "mecanismo pelo qual a sociedade civil e os atores locais em geral não limitam sua ação democrática apenas ao voto, mas participam dos processos de decisão no âmbito da administração pública".
}

Rev. de Direito Urbanístico, Cidade e Alteridade | e-ISSN: 2525-989X | Porto Alegre | v. 4 | n. 2 | p. 16 - 33 | Jul/Dez. 2018 
A democracia representativa acaba por limitar a participação do cidadão no sistema político ao ato de votar em representantes que irão defender seus interesses em todos os aspectos governamentais. Estes representantes eleitos não necessitam de autorização prévia das pessoas que os elegeram para decidir seus atos, ainda que oficialmente os representem (OCHOA, 2008). Desta forma, os representantes eleitos têm a liberdade de agirem como melhor acharem, o que provoca que os povos insatisfeitos com esse modelo democrático busquem uma alternativa de exercer sua cidadania.

Ochoa (2008) e Cunningham (2009) afirmam que os teóricos da democracia participativa, em sua imensa maioria, fundamentam parcialmente este modelo nas ideias de Jean-Jacques Rousseau, excluindo-se questões problemáticas, tais como algumas crenças sexistas do teórico. Estes fundamentos encontram-se particularmente na obra "O contrato social", lançada originalmente em 1762, na qual objetiva-se explicar como a conciliação entre liberdade e submissão pode se dar, analisando o homem ainda no estado de natureza e sua concordância em associar-se e se submeter à uma autoridade política por meio do estabelecimento de uma convenção, ou seja, o momento em que o homem faz a transição deste estado de natureza para o estado civil.

Neste livro, considerado tão incendiário à época que chegou a ser literalmente queimado em cidades como Genebra (cidade natal do autor), Rousseau defende que a população que permite que representantes deliberem e legislem em seu nome não é livre, ainda que assim se reconheça, e propõe a ideia de soberania popular, na qual o poder político soberano é exercido pelos cidadãos organizados em um corpo moral e político coletivo criado de comum acordo, que manifesta uma vontade geral (ROUSSEAU, 1762).

Rousseau (1762) diz que todo homem nasce livre, porém é escravizado com base em uma ordem social definida em convenções, já que apenas a força não produz um direito legítimo que permita essa escravização e por nenhum homem ter de fato autoridade natural sobre outro homem. Quando o homem renuncia a sua liberdade, ele renuncia também aos seus direitos de homem e de humanidade, bem como os deveres correspondentes. Na busca de identificar qual convenção rege a ordem social, deve-se verificar o que o teórico considera como "verdadeiro fundamento da sociedade", que é o ato que constitui o povo como tal (ROUSSEAU, 1762, posição $16 \%)$.

O teórico é veemente ao defender que não há obrigação da minoria se submeter às escolhas da maioria, a não ser que exista uma convenção anterior, ou seja, um pacto social prévio, no qual os cidadãos se unam por associação e cooperação. Neste sentido, deve-se 
“encontrar uma forma de associação que defenda e proteja com toda a força comum a pessoa e os bens de cada associado, e pela qual cada um, ao unir-se a todos, obedeça somente a si mesmo e continue tão livre quanto antes" (ROUSSEAU, 1762, posição 16\%).

Esta busca se encerra quando se identifica o pacto social, cujas regras, ainda que possam não ter sido formalmente enunciadas, são aceitas e reconhecidas tacitamente por todos, de modo que se houver a violação de qualquer delas, o cidadão retorna ao estado prévio de liberdade natural que tinha renunciado em prol da liberdade convencional. Em síntese, estas cláusulas demandam a alienação de todos os pactuantes e seus bens à comunidade como um todo. Nas palavras de Rousseau (1762, posição 17\%): "Cada um de nós põe em comum sua pessoa e todo o seu poder sob a suprema direção da vontade geral; e recebemos, enquanto corpo, cada membro como parte indivisível do todo".

É interessante notar que o teórico relembra que o corpo coletivo moral e político formado por todos os cidadãos que hoje é chamado de República, antigamente era identificado como Cidade, pois que são os cidadãos que fazem a cidade, e não as fortificações (chamadas na obra de "burgos"). Assim, Rousseau afirma que se passou a identificar erroneamente o burgo como Cidade e o burguês (morador do burgo) de cidadão, enquanto que, em verdade, quem constrói e vive a Cidade é o cidadão (ROUSSEAU, 1762).

Logo, a cidade passou a ser identificada como República (ou corpo político) recebendo os seus membros e associados nomenclaturas distintas, de acordo com a perspectiva adotada. A República passa a ser chamada de Estado, soberano ou potência e os associados de povo, cidadãos e súditos.

O pacto social, que torna todos iguais por meio da convenção firmada, infere que as partes contratantes devem se ajudar, contendo um compromisso tácito de que "todo aquele que se recusar a obedecer à vontade geral será forçado por todo o corpo a obedecer, o que não significa outra coisa senão que o forçarão a ser livre, pois tal é a condição que garante o cidadão, entregue à Pátria, de toda dependência pessoal" (ROUSSEAU, 1762, posição 19\%). Isso exemplifica um paradoxo: ao mesmo tempo em que se é negada a liberdade de buscar seus interesses particulares, sua liberdade como cidadão acaba sendo intensificada.

Este corpo político formado pelos associados adquire uma vontade geral, a qual limita a liberdade civil exercida pelos cidadãos, sendo por meio dela que ocorre a promoção de objetivos comuns. Rousseau (1762) ressalta que é incompatível com a vontade geral os interesses particulares, pois que aquela busca a igualdade e o bem comum, enquanto que esta quer os interesses privados de cada um.

Rev. de Direito Urbanístico, Cidade e Alteridade | e-ISSN: 2525-989X | Porto Alegre | v. 4 | n. 2 | p. 16 - 33 | Jul/Dez. 2018 
Neste contexto, apenas podem ser submetidas para discussão e execução questões gerais, sendo a consulta do corpo político feita por meio do ato de expressão de cada cidadão, ou seja, todos os cidadãos por si mesmo apontam suas opiniões sobre o assunto em discussão. Esta vontade geral será bem-sucedida quando realmente identificar esses objetivos comuns, o que depende diretamente do nível de esclarecimento e de educação que o povo tem (ROUSSEAU, 1762).

A soberania, poder absoluto concedido pelo pacto social ao corpo político, nada mais é do que o exercício desta vontade geral, a qual é representada pelo soberano, que é o ser coletivo. O soberano não distingue individualmente os cidadãos, percebendo apenas o corpo político, de modo que todo ato autêntico de vontade geral afeta a todos igualmente, obrigando-os ou favorecendo-os (ROUSSEAU, 1762). Assim, a soberania é

uma convenção do corpo com cada um de seus membros: convenção legítima, pois tem por base o contrato social; equitativa, pois é comum a todos; útil, pois não pode ter outro objeto senão o bem geral; e sólida, pois tem por garantia a força pública e o poder supremo. (ROUSSEAU, 1762, posição 27\%)

O filósofo entende que quem cria a lei é quem melhor compreende como esta deve ser interpretada e executada, não podendo haver desvios das ideias gerais para os interesses particulares. Para que haja uma verdadeira democracia, não é possível que a maioria decida o que a minoria deve fazer, de modo que esta ideia é melhor aplicada em Estados pequenos, nos quais os cidadãos se conheçam e tenham condições mais ou menos equitativas. A população funcionaria tal como um órgão legislativo, construindo as leis a serem executadas pelo soberano (ROUSSEAU, 1762), ideia basilar do modelo de democracia participativa.

Desta forma, o soberano vincula-se ao que a vontade geral quer, sendo mero executor de suas determinações. A democracia, então, pode ser compreendida como o controle do Estado pelo cidadão, que decide os objetivos comuns que devem ser executados pelo soberano. Esta noção se torna problemática quando se enxerga o governo como apenas um representante do corpo político, ao invés de como corpo político em si mesmo na função de soberano, o que pode facilitar um descolamento deste corpo político que crie uma vontade do corpo do governo, o que força os cidadãos a ter que negociar a execução da vontade geral (CUNNINGHAM, 2009).

O modelo de democracia participativa, assim como foi proposto por Rousseau, identifica a sociedade civil e o Estado como sendo a mesma coisa, por conta do pacto social firmado. Neste sentido, a democracia deve ser promovida em todas as instituições da sociedade civil que constituem sistemas políticos em sentido amplo, como nas universidades, nas famílias,

Rev. de Direito Urbanístico, Cidade e Alteridade | e-ISSN: 2525-989X | Porto Alegre | v. 4 | n. 2 | p. 16 - 33 | Jul/Dez. 2018 
no ambiente de trabalho etc. Os cidadãos devem ser engajar nas atividades democráticas locais, sendo a apatia um sintoma de que a vontade geral daquele corpo político não está sendo executada, ou seja, da inefetividade de determinado fórum. A apatia se dá porque as pessoas não têm poder real de decisão. Para Cunningham (2009, p. 154)

\begin{abstract}
A democracia é apropriada quando soluções alternativas a situações problemáticas estão disponíveis; contudo, a tomada de decisão democrática é de valor limitado quando problemas ou soluções alternativas são definidos por pessoas diferentes daquelas que se presume que devam tratar delas e/ou quando há um pequeno controle sobre como ou se soluções aceitas serão implantadas.
\end{abstract}

Rodean (2011) aduz que existe uma desconfiança entre as instituições e os cidadãos, cujo relacionamento deve ser reconstruído. Tradicionalmente, esta desconfiança tem esvaziado a participação dos cidadãos no processo de escolha, criando uma lacuna entre o que o cidadão quer, ou seja, sua demanda social e a habilidade do governo em construir políticas públicas que respondam às exigências da sociedade.

Neste cenário, a construção de uma democracia plena, na qual todos os envolvidos têm o mesmo poder para determinar o resultado de decisões, requer uma participação ampla em todos os estágios de tomada de decisão. Não é aceitável que pessoas que discordam do proposto ou apresentem perspectivas diferentes sejam excluídas de participar de qualquer dos estágios, pois que isso levará à redução de participação dos envolvidos, assim como do próprio entusiasmo das pessoas em participar daquele processo, o que leva ao retorno da apatia (CUNNINGHAM, 2009).

Citizen participation is therefore required for the policy-making process and is made possible only indirectly - by means of widespread consultations - for the policy formulation process. In this sense, the participation of citizen takes on the guise of a wide expertise rather than that of the active collaboration in the processes of formulation and execution. ${ }^{2}$ (RODEAN, 2011, p. 37)

$\mathrm{Na}$ tomada de decisão coletiva democrática, os participantes devem sempre se comprometer a promoção do bem público, estabelecendo o que é melhor para aquela comunidade. Esta busca do bem coletivo pode ser dificultada por conta da inexistência de bens comuns, dada a escassez de recursos e conflitos básicos de interesses, o que pode ser resolvido pela superação do egoísmo e da má distribuição de recursos existentes, bem como pela

\footnotetext{
${ }^{2}$ Tradução livre da autora: “A participação do cidadão é, logo, necessária para o processo de decisão da política e só é ofertado de forma indireta - por meio de amplas consultas - para o processo de formulação da política. Nesse sentido, a participação do cidadão adquire caráter de expertise ampla ao invés de colaboração ativa nos processos de formulação e execução".
}

Rev. de Direito Urbanístico, Cidade e Alteridade | e-ISSN: 2525-989X | Porto Alegre | v. 4 | n. 2 | p. 16 - 33 | Jul/Dez. 2018 
reavaliação da necessidade do consumo exacerbado. Esta mudança de valores se dá pela participação política de cada um e pelo reconhecimento de que os cidadãos são diferentes e devem encontrar um consenso que tenha como mote a igualdade substantiva para resolver suas divergências (CUNNINGHAM, 2009).

Lima (2009) defende que a participação dos cidadãos nos processos é bastante importante para que haja uma melhora concreta da realidade, pois que podem ofertar visões únicas sobre cada assunto. O compartilhamento de informações se daria perante uma gama maior de atores, de modo que os envolvidos seriam, ao mesmo tempo, beneficiários e avaliadores das políticas públicas, aumentando a qualidade dos serviços e obras feitos pelo Estado.

O modelo de democracia participativa não tem como escopo uma mera política paternalista, mas a vontade de se lutar pela sua comunidade e de como cada um deve ser senhor de si mesmo, não representando isso uma contradição da busca pelo comum. A mudança de consciência por um benefício do coletivo em detrimento do individual se dá progressivamente com a participação das pessoas em atos participativos (CUNNINGHAM, 2009).

Existem formas diferentes de participação as quais devem ser aplicadas de acordo com cada sociedade e localidades, de modo que a forma de participação varia de acordo com o que se busca de mudança social e o tempo que se tem disponível para alterar as estruturas existentes. Para Chopra (2004, pp. 298-299), existem dois passos a serem tomados ao se avaliar as formas de participação mais adequadas.

[...] The first step is to assess and to appreciate the dynamics of perception. Popular perspectives will equally affect any form of intervention, however minimal or extensive, in conflict, postconflict, and nonconflict environments and at any level, local or national. [...] The second step is to actually turn collated information into a detailed concept for genuine participation and to design the mechanisms necessary to support social transformations that are both effective and legitimate. ${ }^{3}$

Neste cenário, a participação deve ser direta e, inicialmente, de preferência em arenas pequenas, para que haja o rompimento do domínio da passividade política em que as pessoas se encontram. A participação demanda que todas as opiniões sejam ouvidas e consideradas, de modo que não haja a presença de autoritarismos, respeitando-se as individualidades. $\mathrm{O}$

\footnotetext{
${ }^{3}$ Tradução livre da autora: "O primeiro passo é avaliar e perceber a dinâmica de percepção. As perspectivas populares afetarão igualmente qualquer forma de intervenção, não importando se mínima ou extensa, em ambientes de conflito, pós-conflito e não conflito e em qualquer nível, local ou nacional. [...] O segundo passo é transformar a informação coletada em um conceito detalhado de participação genuína e projetar os mecanismos necessários para apoiar as transformações sociais que são ao mesmo tempo efetivas e legítimas".
}

Rev. de Direito Urbanístico, Cidade e Alteridade | e-ISSN: 2525-989X | Porto Alegre | v. 4 | n. 2 | p. 16 - 33 | Jul/Dez. 2018 
momento da participação exige que cada um dê o melhor de si, dentro de seus talentos e habilidades (CUNNINGHAM, 2009).

O modelo de democracia participativa também auxilia na melhora de aspectos da organização social (como confiança e normas) quando incentiva que os cidadãos empreendam atividades em conjunto, aumentando valores de comunidade, como a solidariedade. Ainda que haja uma dificuldade em aplicar esta teoria em alguns campos, como no direito internacional e até mesmo no municipal (dependendo do porte da cidade), Macpherson apud Cunningham (2009, p. 163) propõe a construção de

\footnotetext{
'um sistema de conselho piramidal' no qual se começa com 'discussões face a face e decisão por consenso ou maioria' no nível local da vizinhança e/ou lugar de trabalho, onde delegados podem ser eleitos para 'compor um conselho no nível seguinte mais inclusivo, por exemplo, bairro, distrito ou município', e assim por diante até o nível da nação.
}

Portanto, o grande objetivo da democracia participativa é identificar quais os obstáculos existentes para a execução da vontade geral e de que formas eles podem ser superados, o que é dificultado por conta da cultura do consumo dominante, que reforça comportamentos individualistas, assim como as abundantes desigualdades econômicas, os quais podem ser superados com a mudança de comportamento do indivíduo e pela construção de uma vontade geral que busque de fato o bem comum e seja executada pelo Estado.

\section{CONCLUSÃO: CONTRIBUIÇÕES DO MODELO DE DEMOCRACIA PARTICIPATIVA À REALIZAÇÃo DO DIREITO À CIDADE}

As inquietações que levaram Lefebvre a desenvolver a noção de direito à cidade há cinquenta anos ainda se perpetuam hodiernamente. A busca pela cidade do encontro e da coexistência, com valores fundamentados na tolerância, é uma necessidade que emerge nos cidadãos sufocados pelo modo tecnocrata de construção do espaço urbano, o qual exerce influência direta em seu modo da vida.

A proposta Lefebvriana de cidade como obra de arte e sua crítica à mera designação de valor de troca do território urbano faz nascer reflexões sobre o custo pessoal desse modo de vida para o indivíduo que é mais autômato e consumidor do que cidadão, bem como a necessidade de mudança de pensamento da sociedade, com a edificação de uma nova consciência urbana coletiva. 
O direito à cidade sob a perspectiva de Harvey, após sua apropriação do proposto por Lefebvre, com escopo último de retomada da cidade pela população cuja finalidade é a gestão democrática do capital no espaço urbano, permite que se vislumbre a possibilidade de mudança na realidade por meio de um possível caminho a ser seguido. Existe realmente uma outra forma de se construir cidades, nas quais o foco principal não seja torna-las apenas mercadorias e em que seus cidadãos possam ter uma qualidade de vida que independa de sua condição econômica.

É interessante notar que Harvey faz um alerta quanto aos múltiplos significados que o direito à cidade pode ganhar, a depender de quem estiver se manifestando sobre ele. Aproveitando-se desta característica, existem ações as quais, sob a justificativa de se buscar o direito à cidade, em verdade acabam por incentivar o oposto ao que este direito propõe, tais como a competição entre cidades (para ver qual consegue lucrar mais com o turismo), a gentrificação, a realização de megaeventos, a financeirização da moradia e da arquitetura etc, os quais não são, na maioria das vezes, pensados priorizando o espaço relacional das pessoas, mas o ganho financeiro que acaba beneficiando uma minoria e não se traduz em melhorias na qualidade de vida dos habitantes da cidade.

A contribuição de Harvey no desenvolvimento do direito à cidade é inestimável, pois que, ao associar esta ideia à teoria econômica marxista na construção de sua própria geografia do capitalismo, conseguiu fazer a transposição desta noção do campo virtual para a práxis. $\mathrm{O}$ direito à cidade não se configurou mais como uma utopia, tendo alcançado status de direito positivado no direito internacional e em diplomas legais brasileiros. É um direito fundamental com o qual ainda não temos muita intimidade.

No ano em que se completam trinta anos da Constituição Cidadã, a primeira a incluir um capítulo (ainda que curto) sobre política urbana após forte pressão popular, deve-se reforçar a importância que os movimentos sociais têm na sociedade democrática. Harvey acredita que a revolução que derrubará o sistema capitalista será urbana e que seus atores principais serão os movimentos sociais urbanos.

A construção da legislação urbanística brasileira deve muito aos movimentos sociais, pois é graças a eles que a pauta legislativa urbana continua avançando, mesmo que a passos um pouco lentos. O legislador brasileiro, eleito para representar a sociedade, não percebeu (ou não se importa) completamente a importância que a legislação urbanística tem para o verdadeiro avanço de uma sociedade livre, justa e igualitária, conforme pleiteia como objetivo nossa Carta Magna. 
Com vistas a incentivar a participação popular na construção do espaço urbano, o Estatuto da Cidade (que regulamentou o capítulo da política urbana na Constituição da República) traz uma seção em que discorre sobre como a gestão democrática da cidade deve ser feita, incluindo, por exemplo, a participação da população na elaboração do plano diretor da cidade e a gestão orçamentária participativa.

Esta gestão democrática deve ser analisada sob o prisma do direito à cidade, não podendo ser realizada por meio de ações fictícias. Não é suficiente que as decisões tomadas se limitem a cumprir formalmente os requisitos de participação previstos na lei, devendo esta gestão ser efetuada de forma efetiva, por meio de real participação democrática da sociedade em todos as etapas de desenvolvimento das políticas públicas urbanas, inclusive na elaboração de instrumentos normativos municipais. Tal controle não deve ser apenas prévio, mas englobar todas as fases das políticas públicas, como planejamento, execução e avaliação. $\mathrm{O}$ arcabouço legal para dar suporte à gestão democrática existe, porém raramente é utilizado adequadamente.

Neste contexto, o modelo de democracia participativa oferta, dentro de sua teoria básica, diversas possibilidades de os cidadãos participarem da construção do espaço urbano. Particularmente, no campo municipal, dada a proximidade entre a sociedade e o gestor, a participação pode ser viabilizada de forma mais fácil, podendo ser realizada por meio de oficinas, reuniões, encontros, audiências públicas, debates etc.

Cada local deve avaliar qual a melhor forma de se propiciar a participação democrática direta de seus cidadãos nas tomadas de decisão e quais estratégias devem ser adotadas para incentivar a participação e evitar a apatia. Também deve-se levar em conta as novas ferramentas que se têm disponíveis atualmente para realizar a democracia participativa, como o acesso à internet, sempre lembrando que, infelizmente, ainda não é um recurso o qual todos têm acesso. O ideal é que haja uma ampliação de instrumentos de acesso do povo ao poder público, com parâmetros firmados conjuntamente, e não verticalmente.

A gestão democrática da cidade, por meio da democracia participativa, ou seja, sem que haja intermediários entre os cidadãos e a tomada de decisão, evita que a sociedade continue a ser uma espectadora da construção do espaço urbano, assim como que o Município centralize em si todas as decisões. A consulta à população sobre o que deve ser feito e como isso se dará deve ser prévia e com amplo acesso à todos, ao contrário do que normalmente acontece, em que a sociedade apenas consegue expressar sua participação durante ou após a execução do ato, o que corriqueiramente traz consequências graves e problemas de difícil resolução.

Rev. de Direito Urbanístico, Cidade e Alteridade | e-ISSN: 2525-989X | Porto Alegre | v. 4 | n. 2 | p. 16 - 33 | Jul/Dez. 2018 
A participação também é uma forma de controle social exercido pelo povo, de modo que haja melhor racionalização. Essa forma de participação maciça, que pode ser incentivada por meio de campanhas educacionais as quais informem à população sobre sua responsabilidade para com a cidade é uma das saídas para descentralizar a tomada de decisões que pode estar restrita a uma cúpula política local.

As campanhas educativas devem apresentar também os canais e mecanismos disponibilizados para a população se manifestar sobre ações municipais, como postos de atendimento, telefones, site etc. Por meio desta abordagem conjunta, em que se motiva o cidadão a participar do processo democrático de escolha e que se disponibiliza as ferramentas para tal, a possibilidade de que esta participação tenha cada vez mais qualidade e continuidade aumenta.

O Município tem a obrigação legal de implementar mecanismos de participação da população, formando uma articulação entre o poder público e o indivíduo, assim como fomentando dentro de cada um a importância do exercício de cidadania. Com os cidadãos participando ativamente da tomada de decisão na cidade, fica mais claro as áreas que devem ser priorizadas, como, por exemplo, quais áreas necessitam de mais investimentos de infraestrutura, em quais áreas devem ser limitadas a instalação de empreendimentos de grande porte etc.

Ainda que o gestor municipal pense que conhece sua cidade, o cidadão detém um conhecimento de sua região mais aprofundado, ultrapassando os levantamentos técnicos. Ao utilizar esse conhecimento, o Município economiza tempo e recursos, bem como otimiza seu processo de aprendizagem. Essa troca de ideia e de experiências também faz com que o cidadão compreenda os desafios que envolvem a construção do espaço urbano e ajuste suas expectativas.

Por fim, enfatiza-se que a participação democrática na gestão urbana não pode ser estanque, devendo estar sempre aberta a revisões, a reavaliações e a melhoras no processo. Não existe uma fórmula única de aplicação do modelo democrático participativo. Ele é construído, vivenciado, experimentado. Deve-se, porém, ter sempre em mente que o corpo político é quem deve tomar as decisões, sendo o Município um executor destas decisões. Quando se reconhece que a cidade é o povo, que o poder soberano é de todos e se reivindica sua construção, é que se consegue dar os primeiros passos em direção à uma sociedade solidária, em que a vida de todos os membros tenha valor de uso.

Rev. de Direito Urbanístico, Cidade e Alteridade | e-ISSN: 2525-989X | Porto Alegre | v. 4 | n. 2 | p. 16 - 33 | Jul/Dez. 2018 


\section{REFERÊNCIAS BIBLIOGRÁFICAS}

CHOPRA, Jarat. Participatory Intervention. Global Governance, Vol. 10, Issue 3 (JulySeptember 2004), pp. 289-306.

CUNNINGHAM, Frank. Teorias da democracia [recurso eletrônico]: uma introdução crítica. Porto Alegre: Artmed, 2009.

HARVEY, David. A produção capitalista do espaço. São Paulo: Annablume, 2005.

The right to the city. New Left Review 53. Sep-Oct, 2008. Disponível em <https://newleftreview.org/II/53/david-harvey-the-right-to-the-city> Acesso 24 jul. 2018.

. Cidades rebeldes: do direito à cidade à revolução urbana. São Paulo: Martins Fontes - selo Martins, 2014.

LEFEBVRE, Henri et al. Du contrat de citoyenneté. Paris: Syllepse et Périscope, 1990.

O direito à cidade. $3^{\mathrm{a}}$ ed. São Paulo: Centauro, 2001.

Espaço e política. Belo Horizonte: Editora UFMG, 2008.

LIMA, Luciano Barbosa de. Gestión y evaluación de participativa de políticas públicas: el caso de los presupoestos participativos. Brazilian Journal of International Law, Vol. 6, Issue 2 (July/December 2009), pp. 251-264.

OCHOA, Christiana. The Relationship of Participatory Democracy to Participatory Law Formation. Indiana Journal of Global Legal Studies, Vol. 15, Issue 1 (Winter 2008), pp. 5-18.

RODEAN, Neliana. Participatory Democracy: Mechanism of Better Regulation in Europe. Acta Universitatis Danubius Juridica, Vol. 2011, Issue 2 (2011), pp. 31-46.

ROUSSEAU, Jean-Jacques. O contrato social. Tradução de Paulo Neves. L\&PM Pocket [Edição Kindle].

SHAKESPEARE, William. Coriolano. Disponível em <https://williamshakespearewilliam.blogspot.com/2009/02/coriolano-ato-iii-cena-i.html >. Acesso em 24 jul. 2018. 